\title{
O Processo de Enfermagem e a Lei do Exercício Profissional
}

\author{
The Nursing Process and the Law of Professional Exercise \\ El Proceso de Enfermería y la Ley del Ejercicio Profesional
}

\author{
Denise Faucz Kletemberg', Márcia T. D. Siqueira", Maria de Fátima Mantovani"',

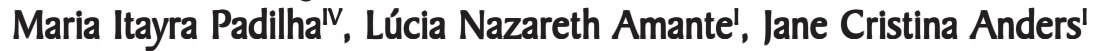 \\ 'Universidade Federal de Santa Catarina. Programa de Pós-graduação em Enfermagem. \\ Grupo de Estudos da História do Conhecimento em Enfermagem. Florianópois, SC \\ "Universidade Federal do Paraná. Departamento de História. Curitiba, PR \\ II'Universidade Federal do Paraná. Departamento de Enfermagem. Curitiba, PR

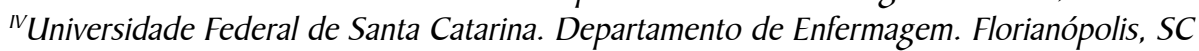

Submissão: $12 / 10 / 2008$

Aprovação: 12/12/2009

\section{RESUMO}

A necessidade da cientificidade no processo de trabalho da enfermagem, impulsionada pelo avanço da ciência e contextualizada no mercado de trabalho, configurou-se na implantação do processo de enfermagem. O objetivo deste estudo foi analisar nos documentos legais de enfermagem, as atribuições do enfermeiro frente à sociedade brasileira, na perspectiva da implantação de metodologia científica no processo de trabalho. Numa abordagem histórica, foram analisados Leis e Decretos-Leis Que normatizaram a prática da enfermagem no período da implantação do processo de enfermagem no Brasil. Nos resultados detectamos Que as enfermeiras das décadas de 1960 a 1980 viram-se pressionadas por cobranças contraditórias das universidades, do mercado de trabalho e Lei do exercício profissional, aliando o planejamento do cuidado à administração, supervisão e ensino.

Descritores: História da enfermagem; Processos de enfermagem; Enfermagem.

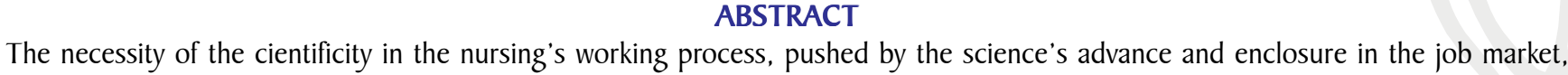
configured itself in the establishment of nursing's process. The purpose of this study was to analyze in the nursing's legal documents, the nurse's duty opposite the Brazilian society, in the perspective of the scientific methodology in the working process. In a historic approach, the laws and designation-laws that normalized the nursing usage in the period that the nursing process was being introduced in Brazil. We detected in the results that the nurses in the 1960's up to the 1980's saw themselves being pushed by the universities' contradictory collections, by the job market and the professional's exercise law, combining the administration care planning supervision and teaching.

Key words: History of nursing; Nursing processes; Nursing.

\section{RESUMEN}

La necesidad de la cientificidad en el proceso de trabajo de la enfermería, impulsada por el avance de la ciencia y contextualizada en el mercado de trabajo, se configuró en la implantación del proceso de enfermería. El objetivo de este estudio fue analizar en los documentos legales de enfermería, las atribuciones del enfermero frente a la sociedad brasilera, en la perspectiva de la implantación de metodología científica en el proceso de trabajo. En un abordaje histórico, fueron analizados Leyes y Decretos-Leyes Que normalizan la práctica de la enfermería en el período de la implantación del proceso de enfermería en el Brasil. En los resultados detectamos Que las enfermeras de las décadas de 1960 a 1980 se vieron presionadas por demandas contradictorias de las universidades, del mercado de trabajo y Ley del ejercicio profesional, uniendo la planeación del cuidado a la administración, supervisión y educación.

Descriptores: Historia de la enfermería; Procesos de enfermería; Enfermería. 


\section{INTRODUÇÃO}

A premissa do empirismo nas práticas do cuidado tem sido contestada, desde a década de 1950 e, por esta razão, os profissionais impulsionados pelo positivismo, pela lógica do sistema capitalista e pelo avanço da ciência buscaram a valorização da enfermagem, ao iniciar a construção de um conhecimento próprio, por meio de elaborações teóricas. No Brasil, o emprego da sistematização das ações de enfermagem ocorreu a partir da publicação do livro "Processo de Enfermagem" de Wanda de Aguiar Horta, na década de 1970. Baseada na teoria das necessidades humanas básicas de Maslow, sob a classificação de João Mohana, ela propôs uma metodologia, a Qual denominou processo de enfermagem. Essa metodologia é permeada pelo método científico e compõe seis etapas: histórico de enfermagem, diagnóstico de enfermagem, plano assistencial, prescrição de enfermagem, evolução e prognóstico de enfermagem ${ }^{(1)}$. Os estudos de Horta impulsionaram o ensino e a pesQuisa da metodologia da assistência de enfermagem no Brasil, pois também coincidiram com o surgimento dos primeiros cursos de mestrado em enfermagem no país.

O desenvolvimento da sistematização da assistência de enfermagem esteve contextualizado nos caminhos percorridos para a profissionalização da categoria no Brasil, Que foi fundada sob interesses do governo, mercado de trabalho e do ensino de enfermagem. Esses interesses refletem-se nas políticas de saúde, Que nas décadas de 1960 e 1970, privilegiavam a prática curativa, individual e especializada e a assistência previdenciária, acarretando a lógica da expansão, direcionando o mercado de trabalho e o ensino de enfermagem para a área hospitalar ${ }^{(2)}$. Foi nesse período de expansão hospitalar, da ênfase nas práticas curativas, da procura pela valorização profissional, Que se inseriu o planejamento da assistência, buscando o embasamento científico no processo de trabalho do enfermeiro.

Este período também se caracterizou pelos esforços da categoria em validar o seu processo de trabalho resultando na aprovação da Lei 7.498, de 25 de junho de 1986. Esta lei regulamentou a prescrição de enfermagem e a consulta de enfermagem como atribuições privativas do enfermeiro, estabelecendo um limite entre as atividades exercidas pelos profissionais da Enfermagem. Esperase evidenciar no contexto histórico e social do Brasil, a legitimação do exercício profissional que se deu a partir das demandas econômicas, sociais e políticas com pouca visibilidade da sociedade usuária deste atendimento de enfermagem e da enfermeira, profissional Que presta este atendimento. Desta forma, o objetivo deste estudo é analisar nos documentos legais de enfermagem as atribuições do enfermeiro frente a sociedade brasileira, na perspectiva da implantação de metodologia científica em seu processo de trabalho.

\section{METODOLOGIA}

Para atingir o objetivo desta pesquisa, optou-se pela pesquisa Qualitativa sócio-histórica de cunho documental, representada pela legislação Que normatiza a categoria, como leis e decretos Que influenciaram a prática da enfermagem A pesQuisa documental é para o pesquisador um dos fundamentos do fato histórico, apresenta-se como prova histórica. $\mathrm{O}$ documento não fica por conta do passado, ele é um produto da sociedade que o faz de acordo com as relações de força Que detém o poder. Ele é composto por elementos Que servem para orientar um entendimento, um conhecimento a respeito de uma época, de um assunto e necessita de uma crítica interna Que revelem as condições de produção histórica, a sua intencionalidade inconsciente ${ }^{(3)}$.

A análise documental ateve-se a decretos-lei formulados nos anos de 1890, 1922, 1923, 1931, 1949 e 1966 e as Leis de exercício profissional de 1955 e 1986, por entender que estas são suficientes para responder a Questão norteadora deste estudo. A discussão a ser empreendida volta-se para dois períodos históricos, aQui determinados pela publicação de leis Que modificaram o exercício profissional da enfermagem. $\mathrm{O}$ primeiro período vai de 1890, Quando foi instituído o ensino para a formação da enfermagem, até a década de 1950, com o Decreto 27.426, de 1949. O segundo período para análise se estende entre 1955 até 1986, referente a publicação das Leis Que modificaram as atribuições para o exercício profissional da enfermagem.

\section{RESULTADOS E DISCUSSÃO}

\section{A profissionalização da enfermagem e sua interface com o contexto político social brasileiro}

No início do século XX, a enfermagem estava sujeita a menos valia do trabalho manual e a sua formação estava restrita aos grandes centros urbanos, Que aliados ao peQueno número de secundaristas no país acarretaram deficit de profissionais nesse período. A política de governo nas décadas de 1960 e 1970 para expansão profissional fez diminuir os ganhos financeiros da categoria, Que, se na década de 1920, era reconhecida como profissão liberal, passou a ser assalariada, com ganhos ditados pelo mercado de trabalho( ${ }^{(4)}$.

O preparo dos docentes e discentes até a década de 1960 era deficitário, haja vista Que em 1956, 64\% das professoras de enfermagem tinham apenas o certificado ginasial. A carreira de nível superior, anseio da categoria desde a implantação do ensino de enfermagem, foi consolidada somente em 1961, com o ingresso efetivo de secundaristas na universidade. Esse fato decorreu das dificuldades de expansão do ensino, o Que também foi comprovado por números, pois, em 1950, haviam 39 escolas, e, em 1974, eram apenas 41 , com a efetivação da pós-graduação somente após a década de $1970^{(5-6)}$.

Portanto, a publicação do artigo de Wanda Horta sobre o processo de enfermagem, em 1971, coincidiu com o processo de Qualificação docente imposto pela reforma universitária, provocando na academia o desenvolvimento de metodologias pedagógicas para seu ensino e sua validação em hospitais-escola. Este fato pode ser comprovado em estudo sobre a história da metodologia da assistência de enfermagem ${ }^{(4)}$, Quando constatou Que existem 47 artigos sobre o tema e suas autoras eram docentes ou profissionais ligadas a centros acadêmicos na época, destacando-se Quantitativamente, escolas de São Paulo e do Rio de Janeiro.

Somava-se à falta de preparo docente a existência de apenas um periódico científico de abrangência nacional na área, nas décadas estudadas, a Revista Brasileira de Enfermagem, Que socializava conhecimentos e experiências da prática para toda a categoria ${ }^{(6)}$. Neste período, a ditadura militar no País estabeleceu a centralização 
do poder e impôs uma rigorosa repressão política, por meio da censura aos meios de comunicação e forte repressão policial. Portanto, a população, na Qual se inseria a categoria da enfermagem, foi alijada de vários direitos e exacerbada de deveres para com a Pátria. Aliavam-se a isso, os preceitos de abnegação e obediência em Que se fundamentava a formação em enfermagem e o número reduzido de profissionais, fatores Que contribuíram para a falta de criticidade apontada por autoras ${ }^{(5)}$ Que procederam análise dos artigos na Revista Brasileira de Enfermagem, no mesmo período.

\section{Primeiro período: 1890 a 1950}

O primeiro ato normativo na enfermagem foi o Decreto Federal 791 , de 27 de setembro de $1890^{(7)}$, Que se transformou no marco histórico da implantação do ensino de Enfermagem no Brasil, criando a Escola Profissional de Enfermeiros e Enfermeiras, no Hospital Nacional de Alienados do Rio de Janeiro. O surgimento dessa escola foi decorrente da crise de pessoal Qualificado no atendimento aos enfermos desse hospital, dado o abandono desse serviço pelas irmãs de caridade ${ }^{(8)}$.

Além de justificar a criação da escola para o preparo de pessoal Qualificado em enfermagem, essa idéia também foi sugerida como solução para o contingente de meninas e mulheres mantidas em orfanatos do Estado e pela filantropia, conforme comentários de José Cesário de Faria Alvin, no texto da Lei, em sua justificativa para criação da escola, ao apontar novos horizontes à mão de obra feminina ${ }^{(7)}$

Apesar do Decreto 791/1890 representar um marco histórico para a enfermagem no Brasil, foi claro o seu enfoque prioritariamente biologicista, cujo currículo enfocava a assistência hospitalar exclusivamente, com aulas ministradas por professores médicos do hospital, formando profissionais voltados para prestar a assistência: o cuidado com o doente e a integração no serviço ${ }^{(4)}$.

A seguir, foi assinado o Decreto 15.799, de 10 de novembro de 1922, Que aprovou o regulamento do Hospital Geral de Assistência do Departamento Nacional de Saúde Pública e em seu artigo $3^{\circ}$ traz a criação da Escola de Enfermeiras do Departamento Nacional de Saúde Pública, anexo aquele hospital, Que em 1926. passaria a chamar-se Escola de Enfermeiras Dona Anna Nery. As atribuições da enfermeira diplomada estavam descritas no artigo 54\%:

Art. 54. A ella incumbirá a organização e distribuição dos serviços e cuidados aos doentes, da cozinha dietética e da rouparia, cabendo-Ihe a responsabilidade pelo bom andamento destes serviços. Os cuidados aos doentes serão orientados pelos médicos-chefes cujas prescripções deverão ser rigorosamente cumpridas $^{(9)}$.

Esse texto deixava transparecer as Questões de gênero, Que sempre estiveram presentes no processo de trabalho da enfermagem, outorgando-lhe tarefas do papel feminino na sociedade: a administração doméstica no fórum hospitalar, ficando responsável pelos serviços de hotelaria, e a subserviência ao médico, detentor do poder pelo conhecimento da ciência e representante do sexo masculino ${ }^{(4)}$. As enfermeiras diplomadas eram as auxiliares superintendentes, como enfermeiras chefe, denominação Que perdurou na sociedade até fins do século XX. Outro dado pertinente foi o parágrafo único do artigo $56^{\circ}$ :
Art. 56. Paragrapho único. Nessas enfermarias todo o serviço de enfermagem ficará a cargo das alumnas ${ }^{(9)}$.

Foi delegado às alunas da Escola todo o serviço de enfermagem das enfermarias, as Quais eram utilizadas como local de aprendizado. A falta de mão-de-obra na área da saúde utilizava o serviço das aprendizes para suprir a escassez de profissionais Qualificados ao serviço. A legislação era o reflexo do interesse do governo daQuela época: a formação de profissionais Qualificados para as práticas do cuidado; a utilização das alunas para suprir o deficit desses profissionais; a imposição dos preceitos de administradora domiciliar; e a subserviência médica.

Por meio do Decreto 16.300, de 31 de dezembro de 1923, aprovou-se o regulamento do Departamento Nacional de Saúde Pública, determinando:

Art. 22 I. A fiscalização do exercício profissional dos médicos, pharmaceuticos, dentistas, parteiras, massagistas, enfermeiros e optometristas será exercida pelo Departamento de Saúde Pública, por intermédio da Inspetoria de Fiscalização do exercício da Medicina ${ }^{(10)}$.

Transparecia, nesse artigo, a hegemonia do poder médico dessa época, ficando sob sua fiscalização o exercício profissional de todas as categorias da área da saúde. Este fato pertence a construção histórica das profissões na área da saúde, alcançando na contemporaneidade esta hegemonia, Quando o médico configura como elemento central do processo assistencial, decidindo sobre o diagnóstico e tratamento e controlando o processo de trabalho em saúde, resultando em uma assistência fragmentada, resultante de um trabalho parcelado e compartimentalizado(II).

O Decreto continuava regulamentando a Escola de Enfermeiras, enunciando o objetivo da escola na formação de enfermeiras profissionais, elencando as atribuições da chefia, estruturação do curso, composição do corpo docente, matrículas e exames. Ressaltavam-se, dentre os requisitos para matrícula:

Art. 4I I. e. attestado de boa conducta, passado pelas autoridades policiaes competentes ou por duas pessoas idoneas, a juízo da directora da escola e da superintendente geral do Serviço de Enfermeiras;

f. Diploma de escola normal, ou documento, Que prove ter instrucção secundaria bastante, a criterio da directora, podendo na hypotese de recusa, ser levado o facto á decisão do Director Geral do Departamento ${ }^{(10)}$.

A exigência do diploma de escola normal ou de instrução secundária caracterizava o esforço de transformar o ensino de enfermagem em ensino de nível superior. Entretanto, a aspiração das enfermeiras norte-americanas Que fundaram essa escola seria plenamente alcançada somente em 1961, devido ao deficit de secundaristas na sociedade brasileira ${ }^{(4)}$. O requisito do atestado de boa conduta mostrava claramente a influência de Florence Nightingale nas enfermeiras norte-americanas e deixou transparecer a sua contribuição na elaboração do texto do decreto. Todavia, compreende-se Que, ao fundamentar o ensino da profissão no país, a intenção tenha sido transformar o estereótipo Que a enfermagem tinha na época, o de profissionais de conduta duvidosa.

Até a década de 1930, os decretos estavam direcionados para 
a regulamentação do ensino. A primeira legislação Que se voltou para o exercício da enfermagem no Brasil foi o Decreto 20.109, de 15 de junho de 1931 . Como justificativa do decreto foi afirmado:

Considerando Que a enfermagem é uma das mais nobres profissões às Quais possa aspirar à atividade humana;

Considerando Que os seus benefícios resultam não só dos cuidados ministrados aos doentes em domicílio ou nos hospitais, mas também da ação preventiva conjuntamente exercida pela enfermeira de saúde pública;

Considerando Que, para o exercício dessa profissão, se vai exigindo nos povos mais adiantados um preparo técnico cada vez mais desenvolvido, outorgando-se mesmo às escolas Que administram esse preparo as regalias de escolas superiores; $[\ldots]^{(12)}$.

O estabelecimento da enfermagem como nobre profissão demonstrava mudanças nas concepções acerca da enfermagem, iniciadas com a fundação da escola Anna Nery, demonstrando Que os esforços das enfermeiras norte-americanas surtiram efeito. Entretanto, essas mudanças iniciaram-se nos grandes centros urbanos, onde foram fundadas as primeiras escolas. No restante do país, as concepções negativas percorreram tempo cronológico maior, determinando, em conjunto com o número reduzido de secundaristas no País, obstáculos à expansão da enfermagem como profissão na década de $1920^{(4)}$.

O reconhecimento da formação de enfermagem em nível superior revelou o prestígio Que a categoria detinha nessa época no poder governamental, já Que essa formação estava restrita a peQueno número de profissões. $\mathrm{O}$ destaque à ação preventiva, como sendo de responsabilidade da enfermagem, evidenciou o interesse do governo nas ações de saúde pública, visto Que ela foi o maior mercado empregador até a década de 1940. Também, mostrou, mais uma vez, o antagonismo Que permeou a instituição da enfermagem como profissão, já Que o currículo da Escola Anna Nery era direcionado para o cuidado hospitalar. A justificativa do Decreto 20.109/3 I retratou também o poder das enfermeiras norte-americanas Que fundaram a Escola Anna Nery, pois esse decreto sacramentalizava essa escola como padrão a ser seguido pelas demais instituições de ensino no País.

Esse decreto fazia referência a titulação, estabelecendo Que enfermeiras diplomadas eram as profissionais formadas por escolas oficiais ou equiparadas, na forma dessa lei, ou diplomadas por escolas estrangeiras reconhecidas no País, pela diretoria da escola Anna Nery. Regulamentava também a eQuiparação de instituições de ensino com essa escola, descrevendo os requisitos básicos e a formação da banca examinadora para tal equiparação.

Apesar de ser a primeira lei de regulamentação profissional, o texto não descreveu as atribuições do profissional, deixando como lacuna o rol dos seus direitos e deveres na sociedade brasileira. $\mathrm{O}$ foco do decreto foi a oficialização do ensino de enfermagem em nível superior e a constituição da escola padrão, determinando o controle do ensino para as enfermeiras norte-americanas fundadoras da escola Anna Nery. A partir deste decreto foi cunhado o termo "enfermeira padrão" ou "enfermeira alto padrão", referindo-se ao padrão Anna Nery de formação de enfermeiras e que se diferenciava dos demais cursos existentes.

Em 1949, foi criada a lei Que regula o curso de enfermagem e o de auxiliar de enfermagem, pela Lei $n^{\circ} 775$, de 6 de agosto de $1949^{(13)}$. Nessa lei foi formalizada a duração do curso de enfermagem em 36 meses e o de auxiliar de enfermagem em 18 meses. Um evidente esforço para a expansão do ensino de enfermagem, ao determinar a criação de escolas de enfermagem em cada centro universitário ou sede de faculdade de medicina, Que ministrasse os dois cursos de enfermagem. O incentivo ao aumento de escolas de enfermagem é revelado no seguinte texto:

Art. 23. O poder executivo subvencionará todas as escolas de enfermagem Que vierem a ser fundadas no país e diligenciará no sentido de ampliar o amparo financeiro concedido às escolas já existentes $^{(13)}$.

Isto demonstrou o interesse governamental e do mercado de trabalho em expandir o ensino de enfermagem e, conseQüentemente, o número de profissionais atuantes no País, Que, Quantitativamente não acompanharam o aumento de instituições hospitalares no Brasil, a partir da década de 1940.

Esta lei, porém, não normatizou o ensino nem as atribuições de cada categoria, lacuna Que foi preenchida somente pela publicação do Decreto 27.426, de 1949, Que aprovava o regulamento básico para os cursos de enfermagem e de auxiliar de enfermagem.

Art. I ${ }^{\circ} \mathrm{O}$ "Curso de Enfermagem" tem por finalidade a formação profissional de enfermeiros, mediante ensino em cursos ordinários e de especialização, nos Quais serão incluídos os aspectos preventivos e curativos da enfermagem.

Art. $2^{\circ} \mathrm{O}$ "Curso de Auxiliar de Enfermagem" tem por objetivo $o$ adestramento de pessoal capaz de auxiliar o enfermeiro em suas atividades de assistência curativa ${ }^{(14)}$.

Ao direcionar as atividades do auxiliar de enfermagem para as práticas curativas, o decreto revelou o interesse de vários setores: do setor privado, Que visava à formação de mão-de-obra barata, para diminuir o emprego de enfermeiras diplomadas; da classe médica, Que necessitava de maior número de auxiliares para o tratamento terapêutico, e para a enfermeira, também foi interessante, pois, devido ao déficit de profissionais, ela poderia delegar funções a um grupo de pessoas mais bem preparado do que o atendente de enfermagem, norteando suas ações para a administração, supervisão e ensino Que lhe eram atribuídas ${ }^{(4)}$.

\section{Segundo período: 1955 a 1986}

Somente em 1955 o exercício profissional da enfermagem foi regulamentado no Brasil pela Lei 2.604/55. Diferentemente da lei de 1931, ela descrevia as atribuições dos profissionais da enfermagem, discorrendo sobre seis categorizações existentes na enfermagem na época vigente: Enfermeiro, Auxiliar de Enfermagem, Obstetriz, Parteira, Parteira Prática, Enfermeiro Prático ou Prático de Enfermagem.

Para as categorias de enfermeiros práticos e parteiras práticas, a lei fixou prazo para a sua descontinuidade, revogando os Decretos 23.774 e 22.257, Que as amparavam legalmente e Que reconheciam os portadores desses certificados até a data da publicação da Lei $2.604 / 55$. Por existirem sete categorias na profissão, Que configurava a formação da equipe de enfermagem, considerou-se necessário especificar as funções atribuídas a cada uma delas, o Que está regulamentado na Lei 2.604/55, em seu artigo $3^{\circ}$, destaca-se o texto relacionado às atribuições da enfermeira: 
Art. $3^{\circ}$ São atribuições dos enfermeiros, além do exercício da enfermagem:

a) direção dos serviços de enfermagem nos estabelecimentos hospitalares e de saúde pública, de acordo com o art. 2 I da Lei n/ 775, de 6 de agosto de 1949;

b) participação do ensino em escolas de enfermagem e de auxiliar de enfermagem;

c) direção de escolas de enfermagem e de auxiliar de enfermagem; d) participação nas bancas examinadoras de práticos de enfermagem $^{(15)}$.

Ao especificar as atribuições das enfermeiras para "além do exercício da enfermagem", a lei não determinou o significado deste termo, porém podemos inferir que este refere-se àQuelas atividades da prática de enfermagem cotidiana. O trabalho manual, de execução das técnicas de enfermagem, não retrataria o 'exercício da enfermagem' descrito na lei? Se assim o era, refletia ele a expectativa da sociedade frente à enfermeira? Apesar da frase ressaltada, o texto da lei descreveu claramente as funções de chefia, administração e de ensino para a enfermeira. A ela caberia prioritariamente a liderança, a condução do serviço de enfermagem Que era o foco da formação destes profissionais, mantendo o preceito da divisão social do trabalho, transcrito no artigo $5^{\circ}$ desta Lei.

$\mathrm{Na}$ análise das atribuições do enfermeiro e do auxiliar e prático de enfermagem, transcritas na lei, percebem-se os preceitos da divisão social do trabalho da enfermagem em intelectual e em manual, ficando a atividade gerencial para o enfermeiro, a Quem compete a coordenação da equipe de técnicos e auxiliares de enfermagem.

Cabe destacar Que o serviço de enfermagem atualmente se organiza sob a divisão parcelar do trabalho e desenvolve-se com relativa autonomia em relação aos demais profissionais, mas ainda está subordinado ao ato assistencial em saúde realizado pelo médico. As enfermeiras assumem a gerência em enfermagem, e além de organizar o processo de trabalho da enfermagem, buscam concretizar as ações realizadas junto aos clientes ${ }^{(11)}$.

A Lei citada demarcava as funções de cada categoria: à enfermeira cabia a administração e o ensino e ao pessoal auxiliar caberiam "todas as atividades da profissão". Essa lei regulamentou o exercício profissional até 1986, Quando a legislação do exercício profissional foi atualizada, portanto, o período da implementação do processo de enfermagem foi regulamentado pela Lei 2.604, de 1955. Com as atribuições da enfermeira claramente definidas para a administração, liderança da eQuipe de enfermagem, regulamentadas tanto na lei do exercício profissional como no ensino, surgiu a preocupação das enfermeiras em organizar a assistência de enfermagem praticada pelos profissionais sob seu comando. No início da década de 60 , surgiu na literatura de enfermagem a utilização de um método científico Que permitia a valorização profissional no mercado capitalista, diferenciando-o dos demais integrantes da equipe de enfermagem para a realização dos cuidados.

Estes novos conceitos nortearam um novo paradigma profissional, Quando o trabalho manual passou a ser valorizado e cobrado pela elite intelectual da categoria. Assim, a enfermeira dos anos 60 viu-se pressionada por cobranças contraditórias das universidades, da prática assistencial hospitalar e da lei do exercício profissional. De um lado, o ensino sofreu mudança radical, preconizando, dentre suas atribuições, o planejamento do cuidado prestado, em dicotomia com a legislação profissional, Que definia como suas atribuições a administração, supervisão e ensino ${ }^{(4)}$.

Nessa mesma década, o governo militar, pressionado pelo mercado de trabalho em conjunto com a pressão popular por mais vagas universitárias, instituiu os cursos profissionalizantes, incluindo o curso técnico em enfermagem. Esse curso profissionalizante iniciou na escola Anna Nery, por meio do Parecer 171/66 $6^{(16)}$. Esse documento descreve as disciplinas que seriam ministradas, bem como as áreas de estágios, como médica, cirúrgica, psieuiátrica e de saúde pública, dentre outras.

Esse parecer contém a mesma lacuna deixada pela legislação de enfermagem em anos anteriores, ou seja, a indefinição das atribuições desempenhadas por essa nova categoria, na equipe de enfermagem. $\mathrm{O}$ Que se percebe, na análise desses documentos, é a criação de uma nova categoria, a fim de aumentar o número de profissionais no mercado a baixo custo, entretanto, sem delimitação de funções. Acrescentava-se a isso a existência de mais uma categoria, atendente de enfermagem, Que era composta por pessoas sem formação especializada, cuja aprendizagem das práticas do cuidado dava-se no serviço de forma empírica. Ela não era considerada categoria legalizada, porém, correspondia à maioria da força de trabalho na enfermagem, até sua extinção, prevista na lei do exercício profissional de 1986. Esse contexto da nãodelimitação de funções correspondentes a cada categoria na equipe de enfermagem deve ter contribuído para as dificuldades encontradas pela enfermeira na aplicação do processo de enfermagem. Se existia a clareza de que competia a ela a supervisão, administração e o ensino, isso não acontecia na delegação das tarefas a serem executadas.

A promulgação da lei do exercício profissional de 1986 foi decorrente da ação conjunta entre a União, a Associação Brasileira de Enfermagem (ABEn), o Conselho Federal de Enfermagem (COFEN) e os Conselhos Regionais de Enfermagem, os Quais conseguiram a aprovação de Lei 7.498, de 25 de junho de 1986, Que atualizava o exercício profissional da enfermagem, e do Decreto 94.406, de 8 de junho de 1987, Que regulamentava esta lei. Muitos de seus artigos foram vetados, outras emendas surgiram, entretanto, a categoria considerou um grande avanço para o desenvolvimento profissional.

No texto dessa lei, a redução das categorias na enfermagem refletiu a realidade profissional, de enxugamento da categoria com a extinção dos enfermeiros práticos e parteiras práticas, tendo sido acrescido a categoria de técnico de enfermagem, criado em 1966. A figura do atendente de enfermagem, Que não constava oficialmente na lei, mas figurava como participante das práticas de cuidado de enfermagem, foi extinta oficialmente, concedendo o prazo de dez anos, a partir da data da publicação da lei, para Que este se Qualificasse. O texto da Lei regulamenta, nos artigos 10 e 11 , como atribuições do enfermeiro:

Art. $10^{\circ}$. O desempenho das atividades de enfermagem constitui o objeto da profissão liberal de enfermeiro, ao Qual é assegurada autonomia técnica de planejamento, organização, execução e avaliação dos serviços da assistência de enfermagem.

Art. I I $\mathrm{O}$ enfermeiro exerce todas as atividades de enfermagem, cabendo-Ihe: 


\section{l) Privativamente:}

a) direção do órgão de enfermagem integrante da estrutura básica da Instituição de saúde pública ou privada, e chefia de serviço e de unidade de enfermagem;

b) Organização e direção de serviços de enfermagem e de suas atividades técnicas e auxiliares nas empresas prestadoras desses serviços;

c) Planejamento, organização, coordenação, execução e avaliação dos serviços de assistência de enfermagem;

h) Consultoria, auditoria e emissão de parecer sobre matéria de enfermagem:

i) Consulta de enfermagem;

j) Prescrição da assistência de enfermagem;

l) Cuidados diretos de enfermagem a pacientes graves com risco de vida;

m) Cuidados de enfermagem de maior complexidade técnica e Que exijam conhecimento de base científica e capacidade de tomar decisões imediatas ${ }^{(17)}$.

Nesta lei, as atribuições de administração e supervisão das unidades de enfermagem permanecem, dando continuidade às atribuições delegadas à enfermeira, desde a implantação da profissão no Brasil. Todavia, algumas atividades da administração desenvolveram-se e outras foram criadas, no período compreendido entre as duas leis do exercício profissional, de 1955 e 1986, como consultoria, auditoria e emissão de pareceres, Que, já na década de 1980, figuravam-se no processo de trabalho dos enfermeiros, advindas da necessidade dos seguros de saúde e medicina de grupo em fiscalizar as atividades prestadas a essas instituições.

A regulamentação da prescrição de enfermagem e da consulta de enfermagem, Que foi conQuista da enfermagem e é de interesse do presente estudo, coroa a trajetória da metodologia da assistência de enfermagem iniciada na década de 1960, desenvolvida com esforços, reflexões, críticas e indiferenças, com a inclusão da sistematização da assistência nessa lei. A aprovação desses instrumentos retratou o reconhecimento da sociedade da necessidade de implantação do método científico no processo de trabalho do enfermeiro. Prossegue o artigo, agora determinando as funções da enfermeira na equipe de saúde:

2) Como integrante da equipe de saúde:

a) participação no planejamento, execução e avaliação da programação de saúde;

b) participação na elaboração, execução e avaliação dos planos assistenciais de saúde;

c) prescrição de medicamentos estabelecidos em programas de saúde pública e em rotina aprovada pela instituição de saúde;

d) participação em projetos de construção ou reforma de unidades de internação;

e) prevenção e controle sistemático da infecção hospitalar e de doenças transmissíveis em geral;

f) prevenção e controle sistemático de danos Que possam ser causados à clientela durante a assistência de enfermagem;

g) assistência de enfermagem à gestante, parturiente e puérpera;

h) acompanhamento da evolução e do trabalho de parto;

i) execução de parto sem distócia; educação visando a melhoria de saúde da população; $|\ldots|^{(17)}$.
A participação da enfermagem na elaboração e avaliação dos programas de saúde já era realidade na prática assistencial. Mais uma vez, a lei vem a reboQue da prática profissional. A participação da enfermagem em programas de saúde coletiva foi impulsionada pela reforma sanitária, Quando os profissionais da área redirecionaram a lógica das políticas de saúde para a promoção da saúde e prevenção de doenças, Que tanto assolavam a população brasileira. Outra atribuição à enfermeira, Que não aparecia na lei do exercício de 1955, era o controle de infecção hospitalar. Essa função também já era exercida pelo enfermeiro, como integrante das Comissões de Controle de Infecção Hospitalar, foco de atenção das autoridades e dos profissionais de saúde.

Grande avanço conQuistado nesta lei foi a delimitação das atribuições das categorias Que compõe a equipe de enfermagem. No entanto, a definição dessas atribuições não foi, e ainda não é, consenso na categoria. Essa insatisfação decorre do número de categorias em uma mesma profissão, divisão ímpar entre as profissões liberais, acrescidas por interesses governamentais e do mercado de trabalho. Apesar dessa polêmica, a promulgação da lei foi um grande avanço para a profissão de enfermagem, pois delimitou o campo de ação dos profissionais, impulsionando-os para a apropriação das funções Que lhe foram atribuídas. No caso da execução da prescrição e da consulta de enfermagem, sua regulamentação refletia os esforços Que a categoria vinha desenvolvendo para obter a visibilidade e a credibilidade desses instrumentos, mostrando a necessidade do embasamento científico no processo de trabalho do enfermeiro e despertando o interesse pela apropriação desses instrumentos por parte dos enfermeiros.

O reconhecimento da importância do processo está evidenciado em artigos recentes, Que advogam Que a aplicação de uma assistência de enfermagem sistematizada é a única possibilidade de o enfermeiro atingir sua autonomia profissional e constitui a essência de sua prática profissional ${ }^{(18)}$.

Assim, as décadas de 1980 e 1990 caracterizaram-se por impulso na metodologia da assistência de enfermagem, com a elaboração da taxonomia da North American Nurses Diagnosis Association (NANDA) e a Classificação Internacional da Prática de Enfermagem (CIPE), dentre outras. Ressalta-se também, os esforços da ABEn Nacional para o desenvolvimento e a validação da Classificação Internacional da Prática de Enfermagem em saúde Coletiva (CIPESC) por tratar-se de uma taxonomia com contribuição brasileira e, portanto, adequada à realidade do país.

\section{CONSIDERAÇÕES FINAIS}

Pode-se observar Que as leis do exercício profissional foram promulgadas para atender a necessidade econômica e política diante de Questões sociais que atravancavam o progresso do país. Exemplos são os primeiros atos normativos Que tiveram como pano de fundo a Qualificação profissional, em um modelo biologicista e apontavam como responsabilidade da enfermeira a organização do serviço, dependência da decisão médica com conotação de uma profissão nobre.

A aprovação da lei 7.498 em 1986 representou um grande avanço em termos de autonomia profissional, de maior clareza na definição de papéis, e uma aceitação da sistematização da assistência de enfermagem como parte das atividades privativas da enfermeira. 
Os profissionais, ao verem estampadas em Lei suas atribuições, sentiram-se responsáveis pela busca de subsídios que fornecessem o referencial para sua implementação. Hoje a sistematização da assistência de enfermagem está presente no cotidiano de trabalho destes profissionais, seja para sua concepção, implementação ou realização. Assim, a lei do exercício profissional e a prática têm relação de reciprocidade.

Porém a sociedade está parcialmente presente neste processo, uma vez Que as leis Que foram promulgadas atendiam a exigência política de mercado e não a população. Tal afirmação é pertinente, pois todos na equipe de enfermagem são reconhecidos como enfermeiros, independente de sua categoria. Para a população, enfermeira é aquela que presta o cuidado, independente da forma como este cuidado é concebido e executado. Por outro lado, as instituições de ensino preparavam o acadêmico de enfermagem para ações de assistência, ensino e gerência, Quando o mercado de trabalho procurava um profissional para gerenciar o serviço, afastando-o do contato direto com a população. Assim perpetuase a divisão entre concepção e realização do trabalho em enfermagem e a população não tem como reconhecer o diferencial da assistência de enfermagem sistematizada porQue desconhece o papel desta profissional.

Embora existam esforços para reverter esta situação, ao se olhar para a história da legalização da profissão de enfermeira, percebese Que lentamente a profissão atendeu indiretamente as necessidades da população, percebidas sob o ponto de vista político e econômico e Que atualmente, a Estratégia de Saúde da Família pode ser o caminho para dar a população o conhecimento sobre o papel da enfermeira e o direito de reivindicar a presença desta profissional ao seu lado.

\section{REFERÊNCIAS}

1. Horta WA. Processo de Enfermagem. São Paulo: EPU; 1979.

2. Almeida MCP, Rocha SMM. O trabalho de enfermagem. São Paulo: Cortez; 1997.

3. Le Goff J. História e memória. Campinas: UNICAMP; 1990.

4. Kletemberg DF. A metodologia da assistência de enfermagem no Brasil: uma visão histórica [dissertação]. Curitiba: Departamento de Enfermagem, Universidade Federal do Paraná; 2004.

5. Silva GB. Enfermagem profissional: análise crítica. São Paulo: Cortez; 1986

6. Germano RM. Educação e ideologia da Enfermagem no Brasil. São Paulo: Cortez; 1983.

7. Brasil. Decreto lei $n^{\circ} 791$, de 27 de setembro de 1890. Crêa no Hospício de Alienados uma escola profissional de enfermeiros e enfermeiras. $9^{\circ}$ fascículo. Diário Oficial República Federativa do Brasil 1890; (9): 2456.

8. Moreira AA. A primeira escola de enfermagem. In: Geovanini, T. História da enfermagem: versões e interpretações. Rio de Janeiro: Revinter; 2002.

9. Brasil. Decreto lei n $15.799 / 22$, de 10 de novembro de 1922. Approva o Regulamento do Hospital Geral de Assistência do Departamento Nacional de Saúde Pública. Diário Oficial República Federativa do Brasil 1922; (1): 21475.

10. Brasil. Decreto lei n'16.300, de 31 de dezembro de 1923. Approva o regulamento do Departamento Nacional de Saúde Pública. Diário Oficial República Federativa do Brasil1924; 3199.
11. Pires D. Reestruturação produtiva e trabalho em saúde no Brasil. São Paulo: Annablume; 2008.

12. Brasil. Decreto lei n 20.109, de 15 de junho de 1931. Regula o exercício da Enfermagem no Brasil e fixa as condições para a eQuiparação das Escolas de Enfermagem e Instruções Relativas ao Processo de Exame para Revalidação de Diplomas. Diário Oficial República Federativa do Brasil 1931; 10516.

13. Brasil. Lei $n^{\circ} 775$, de 6 de agosto de 1949. Dispõe sobre o ensino de Enfermagem no Brasil e dá outras providências. Diário Oficial República Federativa do Brasil 1949 ago; 11729.

14. Brasil. Decreto ${ }^{\circ} 27.426$, de 14 de novembro de 1949. Aprova o Regulamento Básico para os Cursos de Enfermagem e de Auxiliar de Enfermagem. Diário Oficial República Federativa do Brasil 1949 nov; 17517

15. Brasil. Lei $n^{\circ} 2.604$, de 17 de setembro de 1955. Regula o Exercício da Enfermagem Profissional. Diário Oficial República Federativa do Brasil 1955 set; 17738.

16. Santos E. Legislação em Enfermagem: atos normativos do exercício e do ensino de enfermagem. São Paulo: Atheneu; 2002

17. Brasil. Lei 7.498, de 25 de junho de 1986. Dispõe sobre a Regulamentação do Exercício da Enfermagem e dá outras providências. Brasília: Ministério da Saúde; 1986. [citado em 05 mai 2008]. Disponível em: http://www2.camara.gov.br/ internet/legislacao/legin.htm

18. Andrade AC. A enfermagem não é mais uma profissão submissa. Rev Bras Enferm 2007 60(I). 